\title{
Fabrication of Hot \& Cold Water Cum Air Conditioning Dispenser System
}

\author{
${ }^{1}$ G. Venkata Subbaiah, ${ }^{2}$ V. Mallikarjuna, ${ }^{3}$ V. Diwakar Reddy \\ ${ }^{1}$ Assistant Professor, Department of Mechanical Engineering, Chaitanya Bharati Institute of \\ Technology, Proddatur, Kadapa, A.P., India, gvsphd@gmail.com \\ ${ }^{2}$ Assistant Professor, Department of Mechanical Engineering AITS, Rajampeta,
}

A.P., India. mallikarjunav83@gmail.com

${ }^{3}$ Assistant Professor \& HOD, Department of Mechanical Engineering, S.V. University, Tirupati, Chittoor, A.P., India, vdrsvuce@gmail.com

\begin{abstract}
In this paper, an experimental work was develop to produce the hot and cold water simultaneously along with them conditioned air is also obtained all the above stated conditions are obtained by using a one third horse power of the compressor that means it is able to produce the hot and cold water along with conditioning air. The single unit are be helpful enough to survive as a water cooler, geyser and air conditioning. This unit are be utilizes the electricity needed for air conditioner and are be able to survive different purpose by this it is possible to reduce electricity consumption. A hot water at a temperature of $80^{\circ} \mathrm{c}$, cold water temperature at $4^{\circ} \mathrm{c}$ and air condition temperature $22^{\circ} \mathrm{c}$ are produced with this unit. The thermocouples wants to fixed at different points and a digital temperature indicator (dti) by which temperature is be taken through the dti and could calculated the COP of refrigeration and air conditioning and mass flow rate of refrigerant. A heater is provide which help in varying the loads on the unit through the cop of the unit is calculated at the respective loads.
\end{abstract}

Keywords - Fabrication, Dispenser System.

\section{INTRODUCTION}

\section{A. Air conditioning}

Control of temperature, humidity, purity, and motion of air in an enclosed space independent of outside conditions is called air conditioning. In a self contained air conditioning unit, air is heated in a boiler unit or cooled by being blown across a refrigerant filled coil and then distributed to a controlled environment.

Refrigeration air conditioning equipment usually reduces the humidity of the air processed by the system. The relatively cold (below the dew point) evaporator coil condenses water vapour from the processed air,(much like an ice-cold drink will condense water on the outside of the glass), sending the water to a drain and removing water vapour from the cooled space and lowering the relative humidity. Since humans perspire to provide natural cooling by the evaporation of perspiration from the skin, drier air (up to a point) improves the comfort provided. The comfort air conditioner is designed to create a $40 \%-60 \%$ relative humidity in the occupied space. In food retailing establishment's large open chiller cabinets act as highly effective air dehumidifying units.

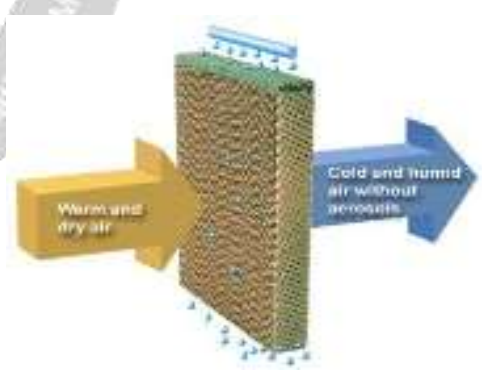

Fig. 1: principle of air conditioning

\section{B. Refrigeration}

Refrigeration is the process of removing heat from an enclosed space, or from a substance and moving it to a place where it is un-objectionable. Remove a bucket of water from a tank, the surrounding water rushes into fill the cavity. Similarly heat rushes into replace the heat when the heat is removed from the refrigerated space. Whatever heat enters through insulation into refrigerated space has to removed with the help of refrigerating machine. Refrigeration is used to cool products. The refrigeration system transfers heat from a cooler low energy reservoir to a warmer high energy reservoir as shown in fig. 


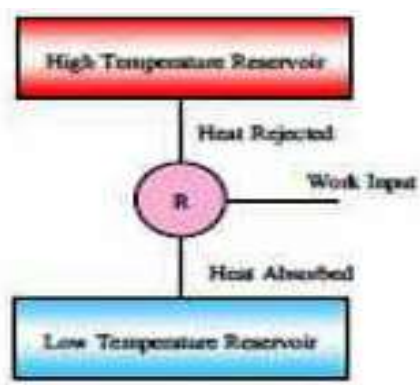

Fig. 2: Schematic representation of refrigeration system

\section{LITERATURE REVIEW}

\section{A. Factors affecting human comfort}

The important factors while designing any system of comfort are

- Effective Temperature

- Heat production \& regulation in human body

- Heat and moisture losses from body

- Moisture content of air

- Quality and quantity of air

- Air motion

- Air stratification

Physiological hazards resulting from heat and extreme cold are

- Heat exhaustion

- Heat cramp

- Heat stroke

- Frost bites

- Hypothermia

- Hyperthermis

Usual Conditions According to the Meteorological Department are

Table 1:

\begin{tabular}{|l|c|l|l|}
\hline S.No. & Contents & Coimbatore & Chennai \\
\hline 1. & DBT & $34.7^{\circ} \mathrm{C}$ & $36.3^{\circ} \mathrm{C}$ \\
\hline 2. & WBT & $27.5^{\circ} \mathrm{C}$ & $28.5^{\circ} \mathrm{C}$ \\
\hline 3. & RH & $58 \%$ & $\mathbf{7 2 \%}^{\circ \%}$ \\
\hline 4. & ET & $30^{\circ} \mathrm{C}$ & $32^{\circ} \mathrm{C}$ \\
\hline
\end{tabular}

\section{B. Vapour compression refrigeration cycle:}

In vapour compression refrigeration system consist four processes. They are

- Compression

- Condensation

- Expansion

- Evaporation

\section{Compression}

The low pressure vapour in dry state is drawn from the evaporator during the suction stroke of the compressor. During compression stroke the pressure and temperature increases until the vapour temperature is greater than the temperature of condenser cooling medium.

\section{Condensation}

When the high pressure refrigerant vapour enters the condenser heat flows from condenser to cooling medium thus allowing vaporized refrigerant to return to liquid state.

\section{$>$ Expansion}

After condenser the liquid refrigerant is stored in the liquid receives until needed. From the receiver it passes through an expansion value where the pressure is reduced sufficiently to allow the vaporization of liquid at a low temperature of about - 10 degree centigrade.

\section{Evaporation}

The low pressure refrigerant vapour after expansion in the expansion valve enters the evaporator on refrigerated space where a considerable amount of heat is absorbed by it and refrigeration is furnished.

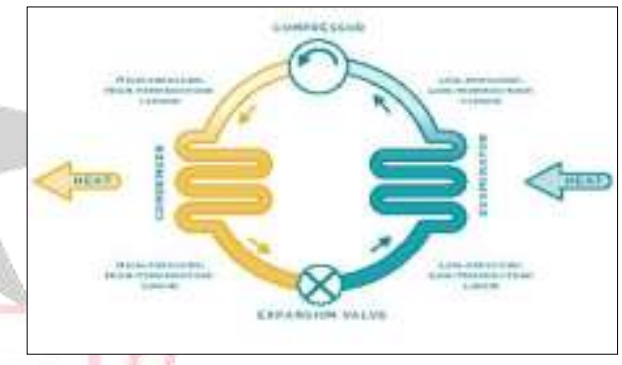

Fig. 3: VCR Processes

\section{Need For Air-Conditioning}

Human beings give off heat around an average of 100 kcal per hour per person, due to what is known as 'metabolism'. The temperature of around $36.9^{\circ} \mathrm{C}\left(98.4^{\circ} \mathrm{F}\right)$. But the skin temperature varies according to the surrounding temperature and relative humidity. To dissipate the heat generated by metabolism in order to maintain the body temperature at the normal level, there must be a flow of heat from the skin to the surrounding temperature is very low, as on a cold winter day the rater of heat flow from the body, and so there cannot be flow of heat from the skin to the surrounding, thus the person feels hot. In such a situation water from the body temperature. But if the surrounding air is not only hot but highly humid as well, very little evaporation of water can take place from the skin surface and so the person feels hot and uncomfortable.

\section{Description of the equipment}

Compressor

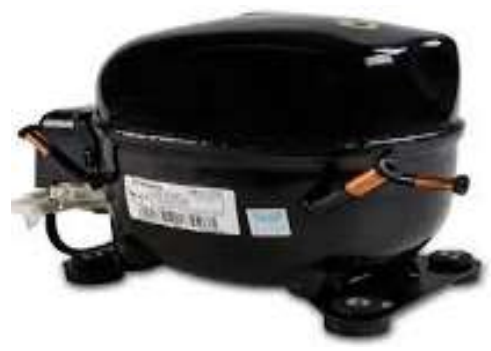

Fig. 4: Reciprocating compressor 
Specification of the Compressor

- Number of cylinders : One

- Working position : Vertical

- Method of compression : Single acting

- Number of times of compression of gas : Single stage

- Cooling system : Air-cooled

- Capacity : 0.5 ton

- Motor used : Single phase

- Speed of the motor : $1400 \mathrm{rpm}$

\section{E. Condenser}

\section{$>$ Introduction}

The condenser is an important device, used in the high pressure side of a refrigeration system. Its function is to remove heat of the vapour refrigerant discharged from the compressor. The hot vapour refrigerant consists of the heat absorbed by the evaporator and the heat of compression added by the mechanical energy of the compressor motor. The heat form the hot vapour refrigerant in a condenser is removed first by transferring it to walls of the condenser tubes and then form the tubes to the condensing or cooling medium.
The quantity of refrigerant admitted in to the evaporator is governed by the valve setting. It is done by turning the adjustment screw to left or right.

\section{G. Shell and Coil Evaporator (Cold Tank)}

The shell and coil evaporators are generally dry expansion evaporators to chill water. The cooling coil is continuous tube that can be in the form of a single or double spiral. The shell may be sealed or open. The sealed shells are usually found in shell and coil evaporators used to cool drinking water. The evaporators having flanged shells are often used to chilled water in secondary systems.

The capacity of the cold tank used in the work is 15 litres. The dimensions of the tank are of $300 \mathrm{~mm}$ diameter and $450 \mathrm{~mm}$ height. The tank, whose diameter is $3 / 8^{\prime \prime}$, through which the refrigerant flows. The cold tank is placed between the expansion valve and the drier which is placed nearer the compressor.

The cold water temperature obtained in the work is $3^{\prime} \mathrm{CM}$ $18^{\circ} \mathrm{C}$.

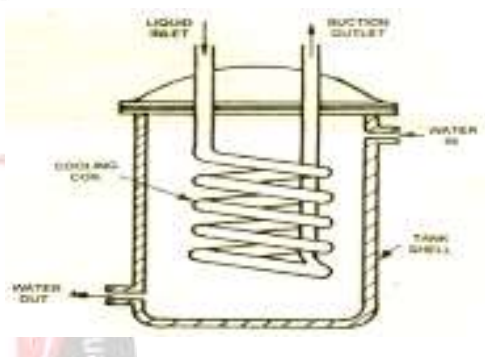

Fig. 7: Shell and Coil Evaporator

\section{H. FREON-22}

This is most widely used and most popular refrigerant of halocarbon group. It condenses at moderate pressures under normal atmospheric conditions. This property makes this refrigerant suitable for all purposes and it can be used with all three types of compressors (Reciprocating, Centrifugal or Rotary). This can be used with all types of condensing units (water cooled, air cooled and evaporative type)

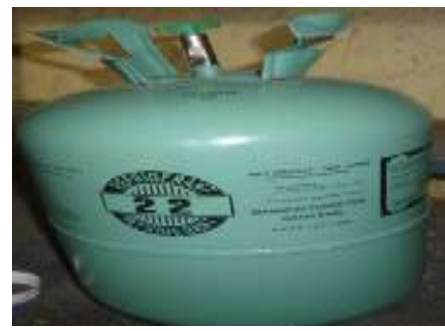

Fig. 8: Cylinder of R-22 refrigerant

As the pressure in the evaporator or low side of the system is reduced by sticking action of the compressor, causes the bellow to expand. This bellow forces the needle to away from the seat and allows the liquid refrigerant to enter in to the evaporator. When the refrigerant pressure rises in the evaporator or low side of the system causes the bellow to contract, then the needle goes back to its seat and stops the entry of the liquid refrigerant to evaporator. This action repeats itself again and again.
$>$ Properties
- Explosive tendency : Non-stable
- Toxic nature : Non-toxic
- Flammable : Non-flammable
- Odour : No objectionable
- Corrosiveness : Corrosive to rubber
- Oil solubility : Completely miscible 
- Chemical stability to working temperature : good

- Electrical insulation : Excellent

- Co-efficient of performance : 4.7

- Critical temperature : $96^{0} \mathrm{C}$

- Critical pressure (bar) : 49.38

- Boling point at atmospheric pressure : $-41{ }^{0} \mathrm{C}$

- Cylinder color code : Green

\section{Leak Detecting Devices}

The leaks occur commonly is every refrigeration system. The leaks should be detected and rectified. Leaks in refrigeration system are usually very tiny. Therefore detecting devices must be very sensitive. Most commonly used are soap bubbles, the halide torch detector and electronic detector.

\section{J. Properties of Copper}

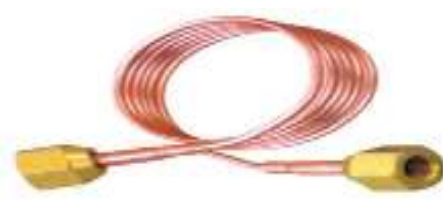

Fig. 9:

Table 2: Properties of Copper

\begin{tabular}{|l|l|}
\hline Density & $8954 \mathrm{~kg} / \mathrm{m}^{3}$ \\
\hline Thermal diffusivity & $0.404 \mathrm{~m}^{2} / \mathrm{hr}$ \\
\hline Specific heat & $0.091 \mathrm{keal} / \mathrm{kg}^{\circ} \mathrm{C} \mathrm{or} 0.381$ \\
& $\mathrm{kj} / \mathrm{kg} \mathrm{k}$ \\
\hline Thermal conductivity & $386 \mathrm{w} / \mathrm{mk}$ \\
\hline
\end{tabular}

\section{FABRICATION}

\section{A. Layout of Project}

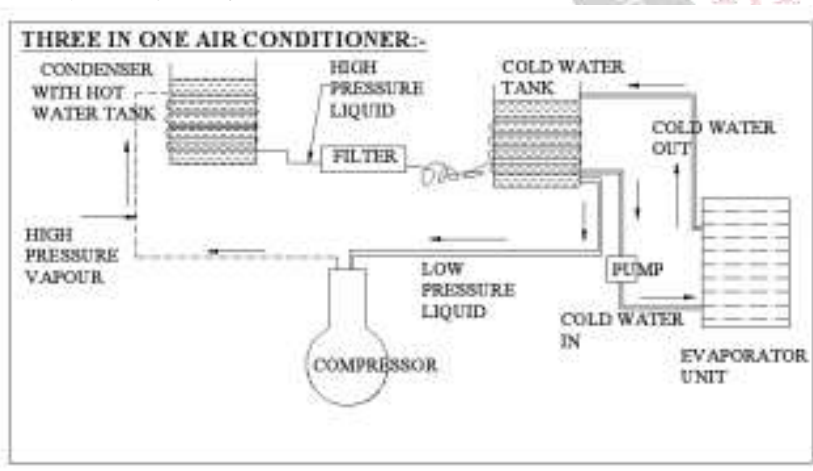

Fig. 10: Layout of project

In the above layout the main objective of this paper is to get the three products from one unit i.e.,

- Hot water

- Cold water and

- Cool air

\section{B. Body of the Unit}

Machine and tools required are,

- Drilling machine.

- Jig-Saw.
- Chisel.

- Nails.

- M.S. Plates and stand

- Nuts and bolts

- Digital thermomete

- Air handling unit

- Switches and board

- Paints

- Copper tube Bender

- Wood.

The duct is the main body of our project which is fabricated by using of M.S. stand and plates. These two parts are join with nut and bolts rigidly. And then it ready to with stand total load of system.

After that make a holes with help of drilling machine to place three water tanks as shown in fig. And again cut a wooden sheet with a specific dimensions trough with help of jig - saw. Wooden block is placed on top of the body at face one side.

A condenser ( 9 " $\times 9$ " $\times 2$ row) is place in the middle of the body and radiator fan is fix at one face of condenser and it join with the discharge line. After condenser an expansion device (capillary tube) is arrange for refrigerant expansion. After expansion the copper tube join with compressor thus the suction line completed. Then the copper pipe arrangement completed.

A condenser ( 9 " $\times 9$ " $\times 2$ row) is place in the middle of the body and radiator fan is fix at one face of condenser and it join with the discharge line. After condenser an expansion device (capillary tube) is arrange for refrigerant expansion. After expansion the copper tube join with compressor thus the suction line completed. Then the copper pipe arrangement completed

A pump is dip in to the one cold water tank and connect with the air handling unit with help of pipes and the outlet of air handling unit is made to flow again in to the tank then it is possible to circulate the cool water in AHU. The pump recirculation the water continuously into the AHU then the air flows through the cooling water coils and then the air became cool.

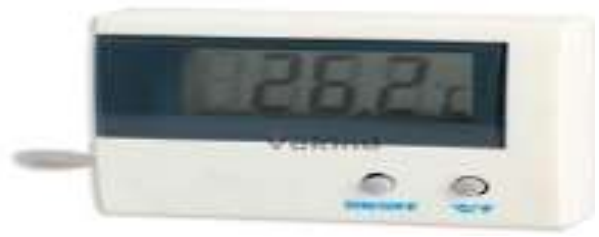

Fig. 11: Digital Thermometers

The refrigerant R22 is used to charging the system. after that switches is make for every individual unit and also place two digital temperature indicators for indication of temperature in hot and cold systems. This indicators give the measurement in both degrees ${ }^{\circ} \mathrm{C}$ and Foreign heats. 
Finally the finishing work done with paints and fevicol. The final finished project is show in the picture.

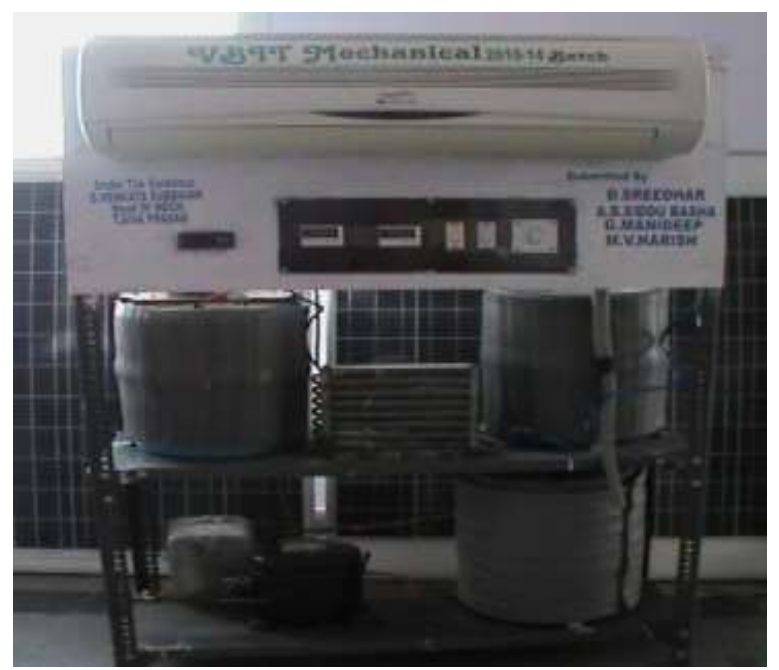

Fig. 12: Fabrication Of Hot \& Cold Water Cum Air Conditioning System
Volts
: $220 \mathrm{~V}$
Amps
$: 1.7 \mathrm{~A}$
Evaporator
: Plate Type
Evaporator Temperature : 45 Degree F
Power Consumption $\quad: 1 \frac{1 / 2}{2}$ unit per hour

\section{Radiator}

Core : : Aluminum

Tube : Aluminum

Cooling : Fan Cooling Type

Volts : $220 \mathrm{~V}$

Amps $\quad: 1.7 \mathrm{~A}$

Evaporator

: Plate Type

Evaporator Temperature : 45 Degree F

Power Consumption $\quad: 1 \frac{1}{2} 2$ unit per hour
Fin Length
: $350 \mathrm{~mm}$
Fin Thickness
$: 0.4 \mathrm{~mm}$
Gap between two fin $\quad: 1 \mathrm{~mm}$
Total No. of tubes : : 49
Capacity
$: 1.25$ litres

Fan

HP $\quad: 1 / 80$

RPM : 1360

Output power $\quad: 9$ watt

AMPS $\quad: 0.3 \mathrm{~A}$

Volts $\quad: 230 \mathrm{~V}$

Frequency $\quad: 50 \mathrm{~Hz}$

\section{B. Capacity of Heating Unit}

Duration of test $=1 \mathrm{hr}$

Volume of water $\mathrm{V}_{\mathrm{w}}=\frac{\pi}{4} \times d^{2} \times h$

$$
\begin{aligned}
\mathrm{d} & =0.24 \mathrm{~m}, \mathrm{~h}=0.3 \mathrm{~m} \\
& =\frac{\pi}{4} \times 0.24^{2} \times 0.30 \mathrm{~m}^{3} \\
& =0.0135 \mathrm{~m} 3
\end{aligned}
$$

Mass of the water $\mathrm{m}_{\mathrm{w}}=\rho_{\mathrm{w}} \mathrm{x} \mathrm{V}_{\mathrm{w}}$

$$
\begin{aligned}
& =1000 \times 0.0135 \\
& =13.57 \mathrm{Kg} / \mathrm{hr}
\end{aligned}
$$

Mass flow rate of water $=13.57 / 3600=0.0037 \mathrm{~kg} / \mathrm{s}$

Quantity of heat added

$$
\begin{aligned}
\text { Qa } 1 & =\mathrm{m}_{\mathrm{w}} \times \mathrm{C}_{\mathrm{pw}} \times\left(\mathrm{Tw}_{2}-\mathrm{Tw}_{1}\right) \\
\mathrm{Tw}_{1} & =20^{\circ} \mathrm{c} ; \mathrm{Tw}_{2}=80^{\circ} \mathrm{c} \\
& =0.0037 \times 4.186 \times(80-20) \\
& =0.92 \mathrm{~kJ} / \mathrm{s}
\end{aligned}
$$

Capacity of heating unit $=0.92 / 3.5=0.26 \mathrm{TR}$

Efficiency of heating coil $=\frac{t d 2-t d 1}{t d 3-t d 1}$

where $t d 3=$ coil temperature $=\frac{80-20}{90-20} \times 100$

$$
=0.85 \times 100=85 \%
$$

\section{Capacity of Cooling Unit}

Duration of test $=1 \mathrm{hr}$

\section{A. Specifications}

$>$ Water Cooler

Name

Compressor

: VOLTAS TUSAR

Condenser

: $1 / 3$ Horse power

Capacity

: 9" $\times 9$ " $\times 2$ Row

Cooling

Volts

: 40liters

Amps

: Fan Cooling Type

$: 220 \mathrm{~V}$

Evaporator

$: 1.7 \mathrm{~A}$

Power Consumption $\quad: 1 \frac{1}{2}$ unit per hour

$\begin{array}{ll}\text { Radiator } & \\ \text { Core } & : \text { Aluminum } \\ \text { Tube } & : \text { Aluminum } \\ \text { Head } & : \text { Plastics } \\ \text { Tube Length } & : 320 \mathrm{~mm}\end{array}$

Volume of water $\mathrm{V}_{\mathrm{w}}=\frac{\pi}{4} \times d^{2} \times h$

$$
\begin{aligned}
\mathrm{d} & =0.24 \mathrm{~m}, \mathrm{~h}=0.45 \mathrm{~m} \\
& =\frac{\pi}{4} \times 0.24^{2} \times 0.45 \mathrm{~m} 3 \\
& =0.02 \mathrm{~m} 3
\end{aligned}
$$

Mass of the water : $m_{w}=\rho_{w} \times V_{w}$

$$
\begin{aligned}
& =1000 \times 0.023 \\
& =20.35 \mathrm{~kg} / \mathrm{hr}
\end{aligned}
$$

Mass flow rate of water $=20.35 / 3600 \mathrm{~kg} / \mathrm{hr}$

$$
=.00565 \mathrm{~kg} / \mathrm{Sec} \text {. }
$$

Quantity of heat removed:

$$
\begin{aligned}
\mathrm{Qr} 1 & =\mathrm{Mw} \times \mathrm{Cpw} \times\left(\mathrm{Tw}_{1}-\mathrm{Tw}_{2}\right) \\
\mathrm{Tw}_{1} & =28^{\circ} \mathrm{c} ; \mathrm{Tw}_{2}=10^{\circ} \mathrm{c} \\
& =.00565 \times 4.186 \times(28-10) \\
& =.4250 \mathrm{KJ} / \mathrm{Sec} .
\end{aligned}
$$

Capacity of water cooling unit: $=.4250 / 3.5=.121 \mathrm{TR}$

Efficiency of cooling coil $:=\frac{t d 1-t d 2}{t d 1-t d 3} \times 100$

where $t d 3=$ coil temperature $=\frac{28-10}{28-6} \times 100$ 


$$
=0.81 \times 100=81 \%
$$

\section{Capacity of Air Conditioner}

Mass of air :- $=\rho_{\mathrm{a}} \times \mathrm{A}_{\mathrm{d}} \times \mathrm{V}_{\mathrm{a}}$

Area of duct $\mathrm{A}_{\mathrm{d}}=\Pi / 4\left(D^{2}\right)$

$$
\begin{aligned}
\mathrm{V}_{\mathrm{a}} & =(\Pi \times \mathrm{D} \times \mathrm{N}) / 60 \\
& =1.2 \times \Pi / 4 \times 0.21^{2} \times(\Pi \times 0.21 \times 1360) / 60 \\
& =0.6209 \mathrm{Kg} / \mathrm{Sec} .
\end{aligned}
$$

Assume that fan efficiency $=80 \%$

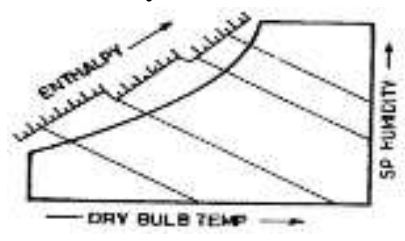

Fig. 13:

Therefore $\mathrm{m}_{\mathrm{a}}=0.6209 \times 0.8=0.49692 \mathrm{Kg} / \mathrm{Sec}$

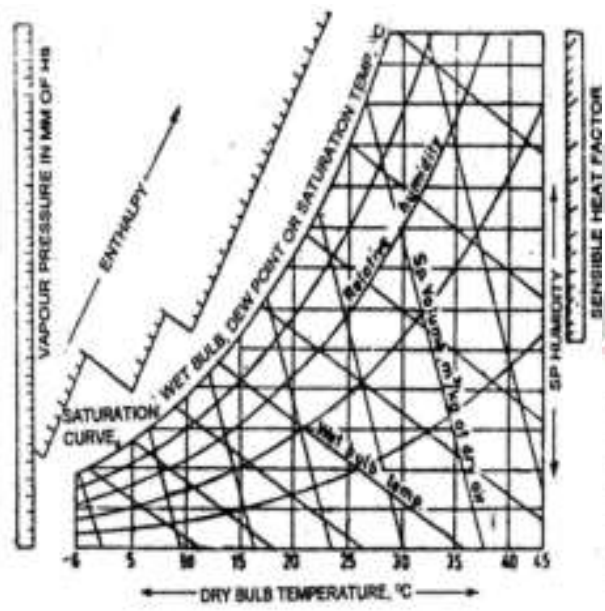

Fig. 14: Psychometric Chart

$\begin{array}{ll}\text { DBT 1 } & =37^{\circ} \mathrm{C} \\ \text { WBT 1 } & =22^{\circ} \mathrm{c} \\ \text { DBT 2 } & =26^{\circ} \mathrm{c} \\ \text { WBT 2 } & =16^{\circ} \mathrm{c}\end{array}$

From table $h_{1}=65 \mathrm{KJ} / \mathrm{Kg} ; h_{2}=45 \mathrm{KJ} / \mathrm{Kg}$

Heat rejection $\mathrm{Q}_{\mathrm{r}}=\mathrm{m}_{\mathrm{a}} \times\left(h_{1}-h_{2}\right)$

$$
\begin{aligned}
& =0.49692 \times(65-45) \\
Q_{r} & =9.9344 \mathrm{~kJ} / \mathrm{Sec} .
\end{aligned}
$$

Cooling capacity of room cooler $=9.9344 / 3.5$

$$
=2.8384 \mathrm{TR}
$$

\section{RESULTS}

The cooling capacity of individual units in the unit and their final temperature that is hot water tank, cold water tank, and air conditioning unit are

Table 3: Results

\begin{tabular}{|l|l|}
\hline Cooling water capacity & $1.2 \mathrm{TR}$ \\
\hline Capacity of hot water unit & $2.6 \mathrm{TR}$ \\
\hline Cooling capacity of room cooler is & $2.8 \mathrm{TR}$ \\
\hline Hot water temperature & $80^{\circ} \mathrm{c}$ \\
\hline Cold water temperature & $4^{\circ} \mathrm{c}$ \\
\hline Temperature of the conditioned air & $22^{\circ} \mathrm{c}$ \\
\hline
\end{tabular}

\section{CONCLUSION}

In this changing modern world every day there is a new discovery in all fields of science and technology, benefiting the mankind. In this work the design of water cooler is slightly modified with an addition air cooler. If one utilizes energy which goes as waste even more useful things can be made.

In this paper 3 units (Hot water unit, Cold water unit \& AC unit) merge as a single unit. With the help of this papert total equipment cost reduces as compared to individual units. These three units works with the help of a single Compressor with a power of $1 / 3$ rd Horse Power. The power consumption is less as it is using a single compressor.

Even middle class people can afford this project as three units are involved into a single unit and also it consumes less power and needs less maintenance.

\section{REFERENCES}

[1] Boast Michael F.Newness refrigeration pocket book , Butterworth Hienmann, 1991 modern refrigerating.

[2] Cerepnalkovski I. machines. Elsevier science publishing 1991.

[3] Refrigeration and air conditioning system R.S Kurmi \& J.K. Guptha, S.Chand\&Co(1996).

[4] Refrigeration and Air Sonditioning A.S Sarao,P.S Gabbi 1998.

[5] Turo machines K .Pandian Akintunde, ma 2004b. experimental investigation of the performance of vapour compression refrigeration system. federal university of technology. Akure, Nigeria, new age publications.

[6] C.P Arora "refrigeration and air conditioning" by eph publications.

[7] Air conditioning engineering W.P. Jones Elbs (1994). 